\title{
Minimizing the bullwhip effect in a single product multistage supply chain using genetic algorithm
}

\author{
Shahed Mahmud*, Md. Sohanur Rahman, Md. Mahamudul Hasan and Md. Mosharraf \\ Hossain
}

Department of Industrial \& Production Engineering, Rajshahi University of Engineering \& Technology Rajshahi-6204, Bangladesh

\begin{tabular}{l}
\hline C H R O N I C L E \\
\hline Article history: \\
Received March 20, 2014 \\
Received in revised format \\
November 18, 2015 \\
Accepted November 182015 \\
Available online \\
November 18 2015 \\
\hline Keywords: \\
Profitability \\
Bullwhip effect \\
Genetic algorithm \\
Optimal ordering quantity
\end{tabular}

\section{Introduction}

Demand variability amplification across the supply chain, known as Bullwhip Effect (BWE), results in serious inefficiencies across the chain. When each player manages its own organization without any coordination to the others, it might cause "Bullwhip Effect" (BWE); variances of ordering patterns move up to the SC from end customer to retailer, to distributor, manufacturer, to Supplier. Lee et.al. (1997a) stated that Procter and Gamble were one of the first companies to identify the bullwhip effect through examining the order patterns for one of their products. Forrester (1958) first demonstrated the term bullwhip effect and motivated many researchers to work on this issue. Lee et al. (1997a) claimed that the merely demand fluctuation in retail shops lead to greater order variability due to information

* Corresponding author

E-mail address: shahed 07ipe@yahoo.com (S. Mahmud)

C 2016 Growing Science Ltd. All rights reserved. doi: $10.5267 /$ j.uscm.2015.11.001

\begin{abstract}
Supply chain management is important for companies and organizations to improve their business and lead competitiveness in the global marketplace. But demand variations in the supply chain are significant problem for most practitioners, planners, demand managers, and operations managers. Demand variations make forecasting and inventory management more difficult and tend to increase inventory levels. The supply chain (SC) profitability can be affected by the cost associated with large inventories, transportation, and production due to the bullwhip effect. Only bullwhip effect can lead to reduce the supply chain profitability in great amount. This paper represents a computational intelligence approach, which addresses the bullwhip effect in multistage supply chain. As a computational intelligence approach, Genetic Algorithm (GA) is employed to reduce the bullwhip effect. Through this approach, optimal order quantity in each stage is to be calculated by considering cost associated with bullwhip effect. Distorted information from one end of a supply chain can lead to tremendous inefficiencies to other end. In this paper it is shown that if each player of the supply chain orders or transfers optimum quantities for the upcoming period then the bullwhip effect can be reduced significantly.
\end{abstract}


distortion and makes the chain inefficient. Burbidge (1995) presented a methodology for controlling production and inventory, which was associated with the problem of BWE and finally provided a thorough definition of BWE: "if demand for products is transmitted along a series of inventories using stock control ordering, then demand variations will increase with each transfer". Croson and Donohue (2006) claimed that decision makers consistently under-weight the supply chain and lead to a form of decision bias that clearly indicates the behavioral causes of BWE. Lee et.al (1997b) identified four major operational causes such as demand signal processing \& non-zero lead time, order batching, price fluctuation, and rationing \& storage gaming, of bullwhip effect and finally claimed that these causes interact with each other and results wild demand swings. They demonstrated that while reacting to any of the four causes above, the strategic interaction of two rational SC members can generate the BWE. Lee et al. (2000) mentioned that information sharing between partners in a supply chain can reduce BWE. Gill and Abend (1997) stated that the most celebrated implementation of demand information sharing is Wal-Mart's retail link program. Chan et al. (2006) noted that the BWE would not exist if there were no forecast based ordering that only attempts to capture the latest demand information. Dejonckheere et al. (2004) and Kelle and Milne (1999) reached the same result. They also mentioned that whatever forecasting model is used, order up to policies will always result in BWE. Potter and Disney (2006) suggested that to mitigate the negative impacts of batching and batch size should be reduced as much as possible. While Riddalls and Bennetts (2002) found that BWE levels are associated with the reminder of the ration between batch size and average demand. Setting batch size at or near the devisor of the average demand rate can reduce BWE. Cachon and Fisher (1999) mentioned that information sharing EDI helps to decrease batch size. They also mentioned that information sharing via EDI can improve operational efficiency by reducing time between processes. As a result order lead time is decreased and BWE also decreases. Wu and Katok (2006) mentioned that the BWE is caused by insufficient coordination between SC agents. Li et al. (2005) introduced the three levels of information sharing between retailer and manufacturer. These are decentralized control, coordinated control and centralized control. The effect of vendor-managed inventory (VMI) on the BWE has been examined by Disney and Towill (2003). Disney et al. (2000) investigated production and inventory control by control theory. Sucky (2009) claimed that BWE may be an overestimated problem. Cachon et al. (2007) and Fransoo and Wouters (2000) made an elaborate attempts to measure BWE empirically. Carlsson and Fuller (2001) employed fuzzy logic to supply chains to decrease the BWE. Kimbrough et al. (2002) created artificial agents via genetic algorithms to reduce the BWE. Merkuryeva and Napalkova (2008) used multi objective simulation based genetic algorithm for multi echelon SC cyclic planning and optimization. O'Donnell et al. (2009) used genetic algorithm to reduce negative effect of sales promotion in SC. Zhou et al. (2002) used genetic algorithm for balancing the allocation of customers to multiple distribution centers in the supply chain network.

After a handsome amount of literature review authors decide that Bullwhip effect is one of the major causes to hamper the supply chain profitability. This paper investigates the demand of each stage of the supply chain and finally recommends the optimal ordering quantity for each member of a SC using GA in order to reduce the bullwhip effect with considering total cost across the entire SC. The exposition of the paper is as follows: Section 2 describes the methodology to reduce Bullwhip Effect; Section 3 is associated with problem formulation, notations and definitions as well as modeling formulation; Section 4 provides numerical example; and finally section 5 presents the contribution of the paper.

\section{Methodology to reduce bullwhip effect}

Reduction of bullwhip effect is a systematic approach. The current problem is also solved step by step. Firstly all the factors which lead to bullwhip effect are taken into consideration. Secondly A constrain linear programming model is built up by considering the most severe factors associated with bullwhip effect in a single product multi-stage supply chain. Thirdly the mathematical model is used to solve a practical problem by collecting relevant data of the model. Genetic Algorithm, a powerful optimization tool that imitates the natural process of evaluation and Darwin's principle of "Survival of the Fittest" is used to solve the problem. And finally the objective of this work is met. 


\section{Problem formulation}

In this paper, authors consider single product multi-stage supply chain. As a multistage, three stages like manufacturer, distributor, and market are considered. This supply chain network is shown is Fig 1. Different types of costs associated with the transportation, production and storage of product are considered to form the mathematical model. The costs are mentioned in later section. The mathematical models to be formed here are divided into three parts: Part1: Minimize SC cost for transferring quantity from manufacture to distribution Centre; Part2: minimize SC cost for transferring quantity from distribution center to market; and part3: minimize the total supply chain cost (TSCC).

\section{Product Flow}

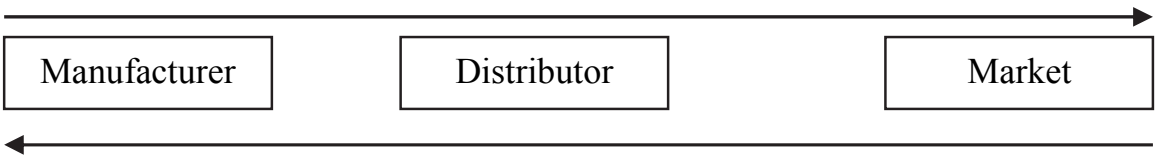

Information Flow

Fig 1. A typical flow diagram of supply chain

\subsection{Notations and Definitions}

The notations which are used in the mathematical model are defined as following.

$i, j=$ indicates the consecutive months, weeks or days or any intervals.

$d=$ no. of distribution center is undertaken among total distribution center for the Plant.

$m=$ no. of market is undertaken among total no. of market for each distribution center.

$C_{i}=$ per unit transportation cost from plant to distribution center in the months, weeks or days or any interval of time

$C_{j}=$ per unit transportation cost from distribution center to market in the months, weeks or days or any intervals of $\mathrm{j}$

$F_{c_{d}}=$ fixed cost of distribution center in the months, weeks or days or any intervals of $\mathrm{j}$

$U P_{c}=$ per unit production cost

$h c_{m}=$ holding cost per unit per days or weeks or months or any intervals for the plant.

$h c_{d}=$ holding cost per unit per days or weeks or months or any intervals for the distribution center.

$X_{i}, X_{i+1}, \ldots \ldots, X_{N \times D}=$ total production quantity in order to meet the demand of distribution centers

$X_{j}, X_{j+1}, \ldots, X_{D \times M \times N}=$ quantity in order to meet the demand of different markets.

Rest of the variables are defined directly in the model

Decision Variables

$X_{i}, X_{i+1}, \ldots \ldots, X_{N \times D}=$ Optimal order quantity transferring from plant to distribution center in the months, weeks or days or any intervals of $i$ 
$X_{j}, X_{j+1}, \ldots, X_{D \times M \times N}=$ Optimal order quantity transferring from distribution center to market in the months, weeks or days or any intervals of $j$

\subsection{Modeling the Problem}

Part 1: Minimize SC cost for transferring quantity from Plant(P) to distribution center (D)

Minimize

$$
C_{P-D}=\sum_{d=1}^{D} \sum_{i=1}^{N} C_{i} X_{i}+U P_{c}\left(X_{i}+X_{i+1}+\cdots+X_{N \times D}\right)-h c_{m}\left(X_{i}+X_{i+1}+\cdots+X_{N \times D}\right)
$$

Constraints:

i. Production capacity constraint

$$
X_{i}+X_{i+1}+\cdots+X_{N \times D} \leq \text { totalunitproduction }
$$

ii. Investment constraint

$$
U P_{c}\left(\sum_{d=1}^{D} \sum_{i=1}^{N} C_{i} X_{i}\right) \leq \text { Totalinvestment }
$$

iii. Order fulfillment constraint

$X_{i}+X_{i+1}+\cdots+X_{N \times D} \leq$ no. of $\mathrm{D} / \mathrm{C} \times$ replenishment frequency $\times$ no.of truck $\times$ unit capacity of each truck

iv. Storage capacity constraint

areaofeach case $\left(X_{i}+X_{i+1}+\cdots+X_{N \times D}\right) \leq$ Areaofwarehouse (plant)

v. Non-negativity constraint

$$
X_{i}, X_{i+1}, \ldots \ldots, X_{N \times D} \geq 0
$$

Part 2: minimize SC cost for transferring quantity from distribution (D)Centre to market (M)

Minimize

$$
C_{D-M}=\sum_{d=1}^{D} \sum_{m=1}^{M} \sum_{j=1}^{N} C_{j} X_{j}+\sum_{d=1}^{D} F_{c_{d}}-\sum_{d=1}^{D} h c_{d}\left(X_{j}+X_{j+1}+\cdots+X_{D \times M \times N}\right)
$$

Constraints:

i. Investment constraint

$$
U P_{c}\left(\sum_{d=1}^{D} \sum_{m=1}^{M} \sum_{j=1}^{N} C_{j} X_{j}\right) \leq \sum_{d=1}^{D}(\text { Total Investment })_{d}
$$

ii. Order fulfillment constraint 


$$
\begin{aligned}
X_{j}+X_{j+1}+\cdots & +X_{D \times M \times N} \\
& \leq \sum_{\substack{d=1 \\
D}}(\text { no. of market } \times \text { replenishment frequency } \times \text { no. of van } \\
& \times \text { unit capacity of each van })_{d}
\end{aligned}
$$

iii. Storage capacity constraint

$$
\operatorname{areaofeachlot}\left(X_{j}+X_{j+1}+\cdots+X_{D \times M \times N}\right) \leq \sum_{d=1}^{D}(\text { Area of warehouse })_{d}
$$

iv. Non-negativity constraint

$$
X_{j}, X_{j+1}, \ldots, X_{D \times M \times N} \geq 0
$$

Part3: minimize the total supply chain cost (TSCC)

Minimize
$\operatorname{TSCC}=C_{P-D}+C_{D-M}$

\subsection{Genetic Algorithm}

Genetic algorithm (GA), replicates the mechanism of biological evolution and natural selection process is a popular global search meta-heuristic algorithm for solving complex optimization problem. The fittest individuals have the highest chance of survival is the base of the GA. The genetic algorithm works with an initial population and each initial population consists of set of initial solutions, represented by chromosomes. Each individual solution or chromosome carries encoded information represented by genes that are assigned to variables. GA works interactively and improves the population of solutions using three search operators which are selection, crossover, and mutation. The selection operator selects the individuals as parents and allows to produces children for the next generation. It gives the preference to the fittest individuals. The crossover operator, a genetic operator generates new chromosomes by combining pairs of existing potential and fitter chromosomes to be let them playing role of parents to produce the next generations. Mutation operator is also a genetic operator that maintains the diversity by making small changes on genes of individual solutions. The process continues until the stopping criteria are met. A typical procedure of the GA is shown in Fig. 2. The genetic algorithm options which are used in solving the problem are as follows: Population Type: Double vector; Population size: 50; Population creation function: constraint dependent; Selection function: stochastic uniform; Elite count: 0.05; Crossover fraction: 0.8; Crossover function: Scattered; Mutation function: constraint dependent.

\section{Numerical example}

Transcom Beverage Limited (TBL) is a leading beverage company in Bangladesh. To test the practicality of the proposed model for Bullwhip effect, this company is considered to carry out the research. TBL has its own strategy to produce and complete the supply chain of 7UP product that is considered of this research work as a single product. They have many distribution centers throughout the country in which TBL supplies its product. Then each distribution centers transfer the product to different markets. In this case study TBL is considered as manufacturer and with four distribution centers such as Vision Enterprise, Badda (VEB), Gazi Corporation, Gulshan(GCG), Salehea Traders, Banani (STB), and Kuril Express, Sahzadpur (KES) and several markets (nM) associated with each distribution center. The considered distributor centers are located within Dhaka region because it is overpopulated. Demand fluctuation is more there and study suits those regions much more. All relevant 
142

data are shown in Table 1. Fig. 3 depicts the variation of demand from market to distribution center to manufacturer. In the figure, the demand graph demonstrates that the demand from the five markets to the VEB and the demand from the VEB to TBL are not perfectly coincided. As a result, there is gap in between two demand patterns. In the same way, Figs. (4-6) present the corresponding demand gap from the markets to distribution centers and the distribution centers to manufacturer.

Start with an initial population and each initial population consists of set of chromosomes.

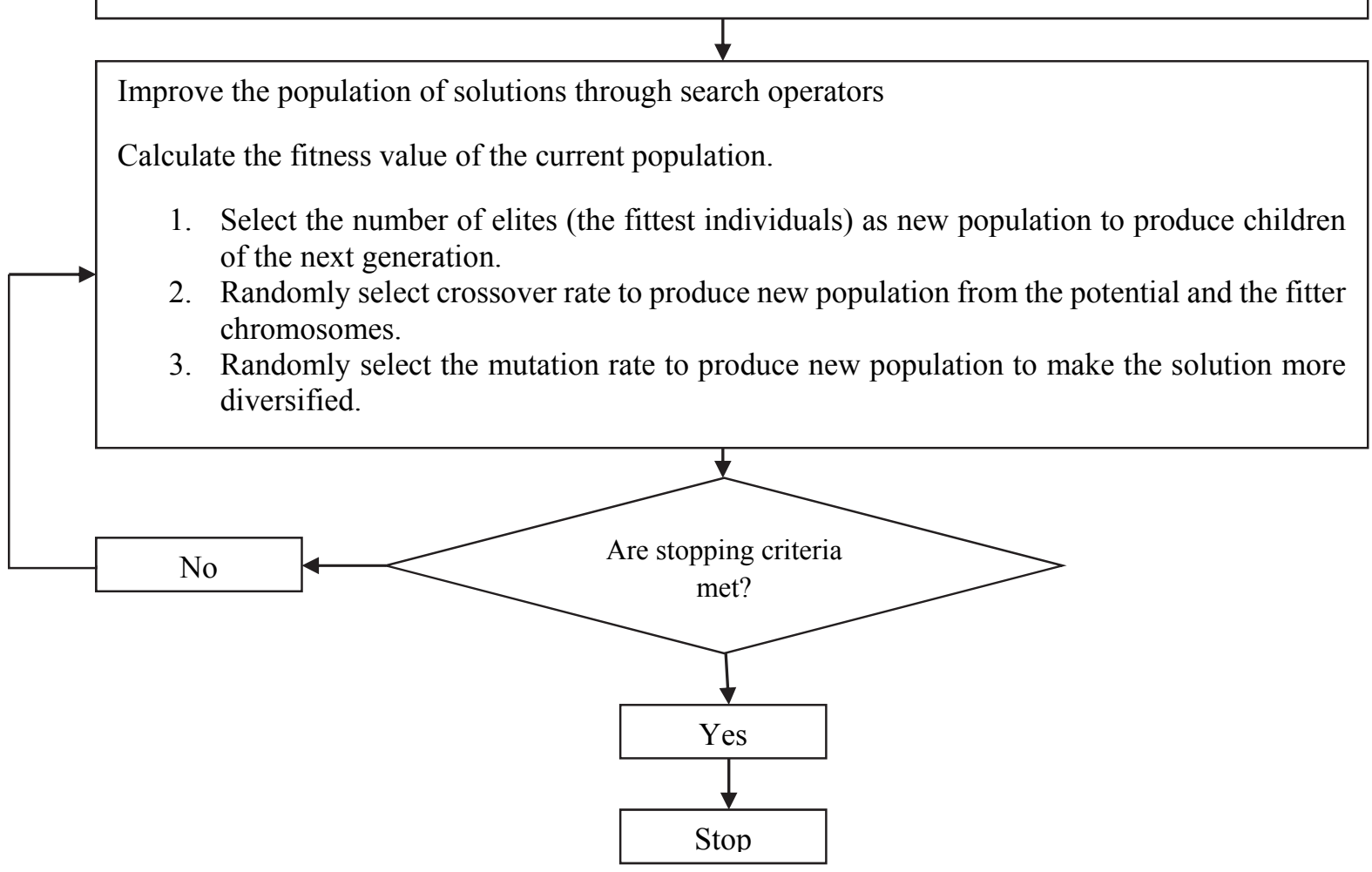

Fig. 2. General procedure of genetic algorithm

Table 1

Demand data of different stages in supply chain

\begin{tabular}{|c|c|c|c|c|c|c|c|c|c|c|c|c|}
\hline \multirow{2}{*}{$\begin{array}{l}\text { Demand } \\
\text { From }\end{array}$} & \multicolumn{12}{|c|}{ Monthly demand in quantity } \\
\hline & Jan & Feb & March & April & May & June & July & August & Sep & Oct & Nov & Dec \\
\hline VEB to TBL & 6250 & 6512 & 12172 & 15369 & 11187 & 15058 & 12301 & 9875 & 6100 & 8850 & 4500 & 2500 \\
\hline $5 \mathrm{M}$ to $\mathrm{VEB}$ & 4446 & 6929 & 12823 & 13757 & 11055 & 14621 & 11174 & 10473 & 5485 & 9214 & 3595 & 3125 \\
\hline GCG to TBL & 7175 & 7833 & 11612 & 13985 & 15426 & 14211 & 11102 & 8625 & 5465 & 7741 & 4225 & 3045 \\
\hline $4 \mathrm{M}$ to $\mathrm{GCG}$ & 5465 & 7450 & 10850 & 14375 & 14220 & 13525 & 9403 & 7888 & 6005 & 8880 & 3985 & 2612 \\
\hline STB to TBL & 5533 & 6995 & 13510 & 14405 & 13945 & 12749 & 13655 & 9721 & 5800 & 6765 & 5012 & 2946 \\
\hline $5 \mathrm{M}$ to STB & 4325 & 7150 & 12439 & 13840 & 14350 & 12884 & 12450 & 10245 & 4946 & 7554 & 5845 & 3410 \\
\hline KES to TBL & 6840 & 7625 & 12385 & 13995 & 14321 & 13051 & 10840 & 8648 & 6321 & 7254 & 4302 & 2100 \\
\hline $6 \mathrm{M}$ to $\mathrm{KES}$ & 5840 & 8225 & 11440 & 14465 & 14100 & 12945 & 11510 & 7546 & 5520 & 7325 & 4885 & 2585 \\
\hline
\end{tabular}




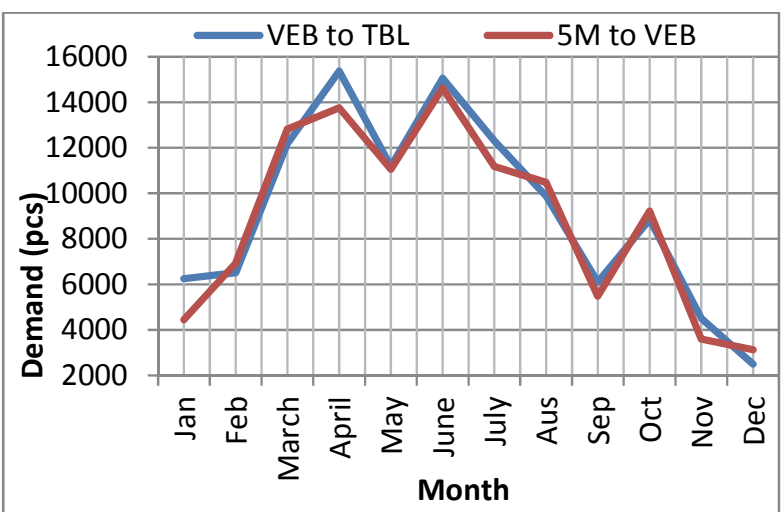

Fig. 3. Demand variation from Market to VEB to TBL

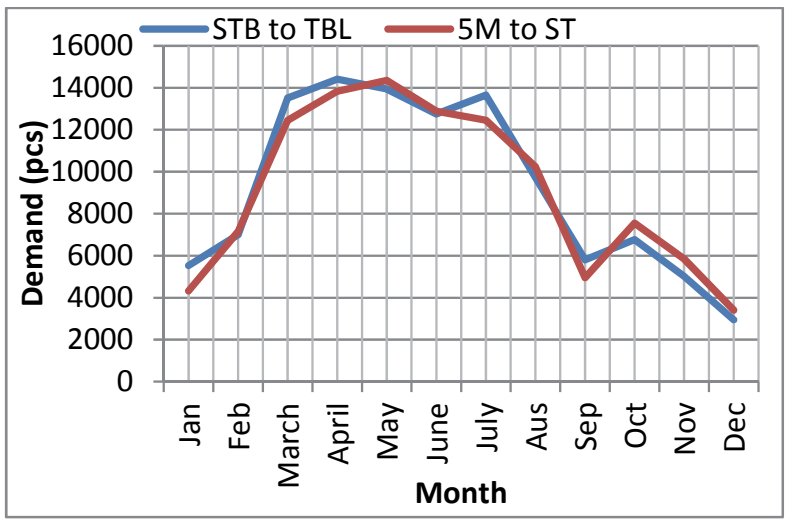

Fig. 5. Demand variation from Market to STB to TBL

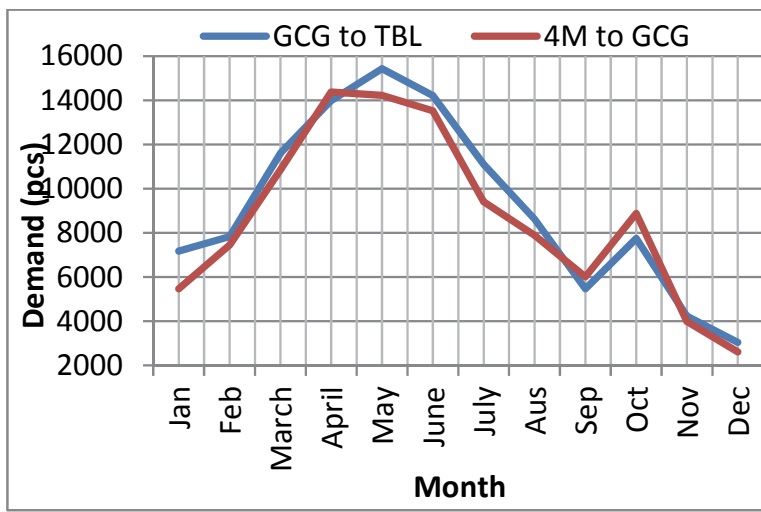

Fig. 4. Demand variation from Market to GCG to TBL

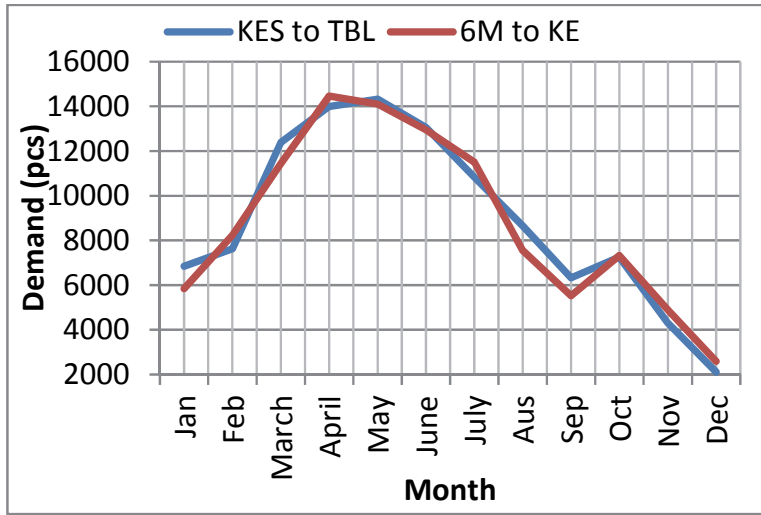

Fig. 6. Demand variation from Market to KES to TBL

Table 2

Transportation cost per unit transfer

\begin{tabular}{lcccccccccccc}
\hline Players & \multicolumn{10}{c}{ Cost per unit transportation in supply chain } & & \\
& Jan & Feb & March & April & May & June & July & August & Sep & Oct & Nov & Dec \\
\hline TBL to VEB & 4.34 & 2.85 & 1.60 & 1.44 & 1.19 & 1.42 & 1.87 & 1.49 & 2.41 & 1.66 & 3.26 & 5.88 \\
VEB to 5M & 8.12 & 8.06 & 7.60 & 7.44 & 7.75 & 7.35 & 7.80 & 7.00 & 7.46 & 8.24 & 8.45 & 8.40 \\
TBL to GCG & 4.33 & 3.02 & 2.51 & 1.45 & 1.31 & 1.21 & 1.90 & 1.72 & 1.85 & 1.64 & 2.64 & 4.20 \\
GCG to 4M & 6.40 & 5.02 & 4.51 & 4.45 & 4.31 & 4.21 & 4.90 & 4.72 & 4.85 & 4.64 & 5.64 & 6.20 \\
TBL to STB & 2.35 & 3.15 & 1.54 & 1.31 & 1.17 & 1.44 & 1.11 & 1.20 & 1.28 & 1.43 & 2.62 & 4.98 \\
STB to 5M & 9.35 & 10.2 & 9.54 & 9.31 & 9.17 & 9.44 & 8.11 & 10.2 & 10.28 & 11.43 & 2.62 & 4.98 \\
TBL to KES & 2.32 & 1.69 & 1.30 & 1.00 & 0.92 & 0.96 & 1.04 & 1.05 & 1.12 & 1.17 & 2.81 & 4.29 \\
KES to 6M & 12.3 & 11.7 & 11.30 & 11.0 & 10.92 & 10.96 & 11.04 & 11.1 & 11.12 & 11.17 & 12.8 & 13.3 \\
\hline
\end{tabular}

The transportation cost per unit transfer from the manufacturer to distribution center and the distribution center to markets are shown in Table 2. Area in warehouse of plant is 15000 Square feet and area in warehouse in distribution centers like VEB, GCG, STB, and KES are 3500, 3250, 3225, and 3245 square feet and respective holding cost (taka) per unit per year are 5.25, 3.5, 2.25, and 2.75, respectively. Holding cost in plant is 5.14 taka per unit per year and average production cost per unit is 20 to 23 taka. GA, general procedure and the search operators adopted are already mentioned in section3.3 is applied by using MATLAB software. The objective function value is obtained Tk. 90,355. The optimal ordering quantities of each stage in the supply chain are shown in Table 3. 
Table 3

Optimal ordering quantity of different stages in supply chain

\begin{tabular}{|c|c|c|c|c|c|c|c|c|c|c|c|c|}
\hline \multirow{2}{*}{$\begin{array}{l}\text { Ordering } \\
\text { From }\end{array}$} & \multicolumn{12}{|c|}{ Monthly optimal ordering quantity } \\
\hline & Jan & Feb & March & April & May & June & July & August & Sep & Oct & Nov & Dec \\
\hline VEB to BL & 6250 & 6514 & 12174 & 15368 & 11186 & 15056 & 12300 & 9876 & 6104 & 8853 & 4498 & 2503 \\
\hline $5 \mathrm{M}$ to VEB & 4447 & 6927 & 12822 & 13758 & 11056 & 14622 & 11175 & 8471 & 5486 & 7213 & 3596 & 3124 \\
\hline GCG to TBL & 7174 & 7833 & 11611 & 13986 & 15426 & 14209 & 11100 & 8623 & 5466 & 7743 & 4424 & 3043 \\
\hline $4 \mathrm{M}$ to $\mathrm{GCG}$ & 5466 & 7450 & 10851 & 14373 & 14222 & 13525 & 9405 & 7889 & 6004 & 8878 & 3986 & 2613 \\
\hline STB to TBL & 5532 & 6996 & 13509 & 14404 & 13946 & 12750 & 13654 & 9722 & 5799 & 6766 & 5015 & 2948 \\
\hline $5 \mathrm{M}$ to STB & 4326 & 7149 & 12440 & 13842 & 14348 & 12883 & 12452 & 10244 & 4948 & 7553 & 5844 & 3408 \\
\hline KES to TBL & 6839 & 7626 & 12383 & 13997 & 14320 & 13050 & 10841 & 8649 & 6320 & 7254 & 4303 & 2101 \\
\hline $6 \mathrm{M}$ to KES & 5841 & 8224 & 11439 & 14464 & 14101 & 12947 & 11508 & 7545 & 5521 & 7322 & 4884 & 2584 \\
\hline
\end{tabular}

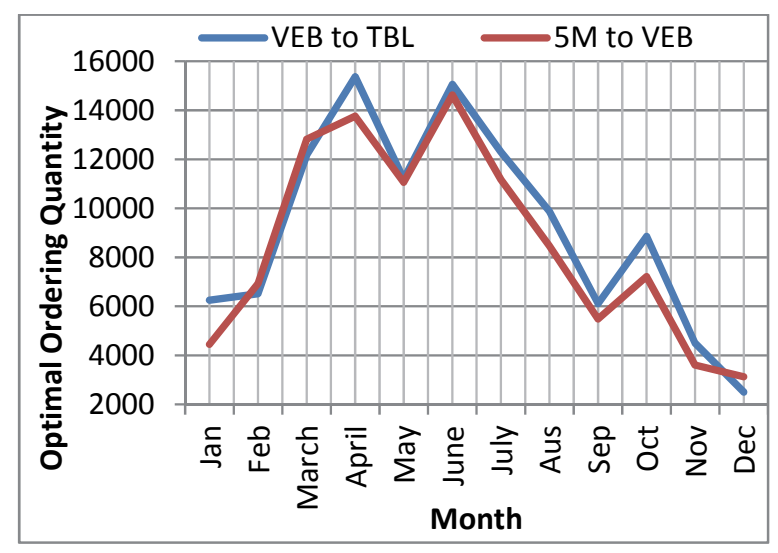

Fig. 7. Optimal quantity transfer from TBL to VEB to market with minimum BWE

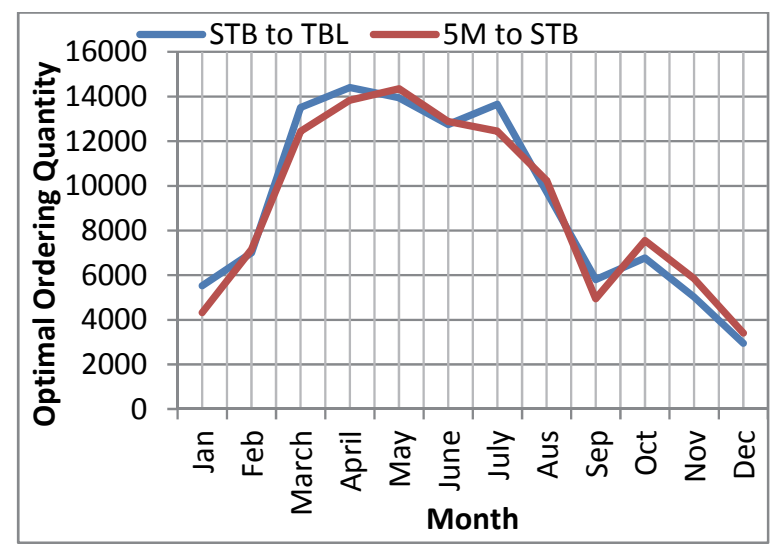

Fig. 9. Optimal quantity transfer from TBL to STB to market with minimum BWE

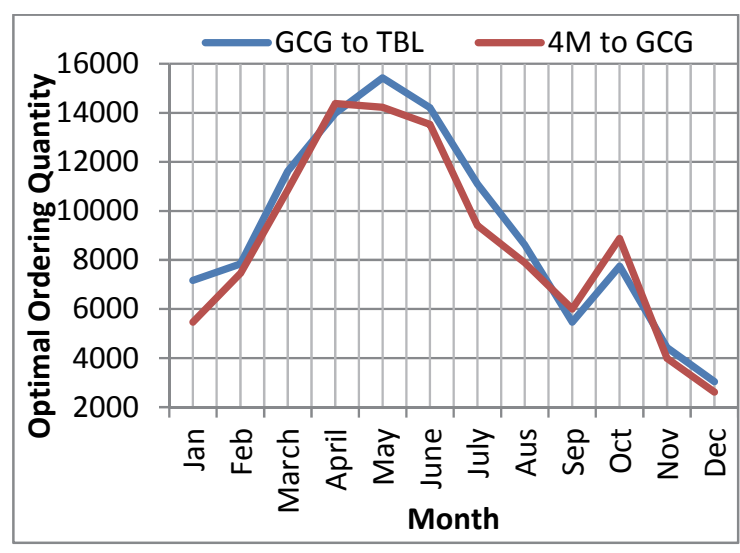

Fig. 8. Optimal quantity transfer from TBL to GCG to market with minimum BWE

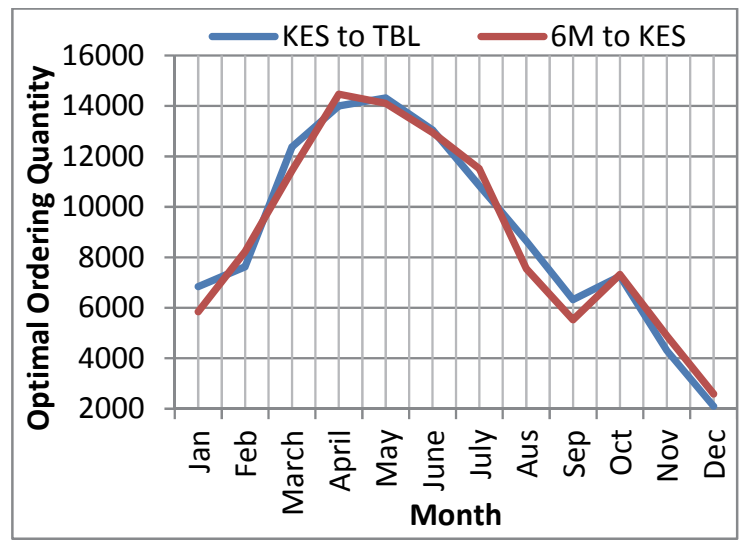

Fig. 10. Optimal quantity transfer from TBL to KES to market with minimum BWE

If a comparison is made in between Table 1 and Table 3 it clearly indicates that the ordering quantity in each month and in each stage of the supply chain is the same or somewhat increases or decreases. Furthermore the ordering curves from plant to distribution center to market shown in Figs. (7-10) are more coincidental than the demand variation curve from market to distribution center to manufacturer shown in Figs. (3-5), and Fig. 6, respectively. It indicates the reduction of variability in between the demand and supply of product in supply chain. So if optimal ordering policy is followed then BWE will be reduced. Finally if this model is used then annual cost will be reduced and BWE effect will also be reduced in great amount. 


\section{Conclusion}

This research has focused on developing a genetic algorithm model for reducing the bullwhip effect in a single product, multi-stage supply chain. The flexibility of this proposed model is the ability to identify optimal ordering quantity for each stage of supply chain. The study has proposed a procedure to reduce the bullwhip effect based on different cost data, improving information sharing levels, and contributions and operational efficiency by identifying optimal ordering quantity in order to perfect match with the demand and supply in the supply chain network. A practical supply chain has been implemented as a case study to validate and to demonstrate the flexibility of the proposed model. The case study was the supply chain of a beverage company named transcom beverage limited. It presents multi-product and multi-stage supply chain but only single product and multi-stage has been considered. The bullwhip effect of this case study has been significantly decreased by using the proposed genetic algorithm.

\section{References}

Burbidge, J. (1995). Back to production management. Manufacturing Engineer,74(2), 66-71.

Cachon, G. P., \& Fisher, M. (2000). Supply chain inventory management and the value of shared information. Management science, 46(8), 1032-1048.

Cachon, G. P., Randall, T., \& Schmidt, G. M. (2007). In search of the bullwhip effect. Manufacturing \& Service Operations Management, 9(4), 457-479.

Carlsson, C., \& Fullér, R. (2001, January). Reducing the bullwhip effect by means of intelligent, soft computing methods. In System Sciences, 2001. Proceedings of the 34th Annual Hawaii International Conference on (pp. 10-pp). IEEE.

Chan, C., Cheng, C., \& Huang, S. (2006). Formulating ordering policies in a supply chain by genetic algorithm. International Journal of Modelling and Simulation, 26(2), 129.

Croson, R., \& Donohue, K. (2006). Behavioral causes of the bullwhip effect and the observed value of inventory information. Management Science, 52(3), 323-336.

Dejonckheere, J., Disney, S. M., Lambrecht, M. R., \& Towill, D. R. (2004). The impact of information enrichment on the bullwhip effect in supply chains: A control engineering perspective. European Journal of Operational Research,153(3), 727-750.

Disney, S. M., \& Towill, D. R. (2003). Vendor-management inventory and bullwhip reduction is a twolevel supply chain. International Journal of Operations and Production Management, 23(6), 625651.

Disney, S. M., Naim, M. M., \& Towill, D. R. (2000). Genetic algorithm optimisation of a class of inventory control systems. International Journal of Production Economics, 68(3), 259-278.

Fransoo, J. C., \& Wouters, M. J. (2000). Measuring the bullwhip effect in the supply chain. Supply Chain Management: An International Journal, 5(2), 78-89.

Forrester, J. W. (1958). Industrial dynamics: a major breakthrough for decision makers. Harvard business review, 36(4), 37-66.

Gill, P., \& Abend, J. (1997). Wal-Mart: The supply chain heavyweight champ.Supply Chain Management Review, 1(1), 8-16.

Kimbrough, S. O., Wu, D. J., \& Zhong, F. (2002). Computers play the beer game: can artificial agents manage supply chains?. Decision support systems,33(3), 323-333.

Kelle, P., \& Milne, A. (1999). The effect of (s, S) ordering policy on the supply chain. International Journal of Production Economics, 59(1), 113-122.

Lee, H. L., Padmanabhan, V., \& Whang, S. (2004). Information distortion in a supply chain: the bullwhip effect. Management science, 50(12_supplement), 1875-1886.

Lee, H. L., Padmanabhan, V., \& Whang, S. (1997). The bullwhip effect in supply chains1. Sloan management review, 38(3), 93-102.

Lee, H. L., So, K. C., \& Tang, C. S. (2000). The value of information sharing in a two-level supply chain. Management science, 46(5), 626-643. 
Li, G., Wang, S., Yan, H., \& Yu, G. (2005). Information transformation in a supply chain: a simulation study. Computers \& Operations Research, 32(3), 707-725.

Merkuryeva, G., \& Napalkova, L. (2008). Development of multi-objective simulation-based genetic algorithm for supply chain cyclic planning and optimisation. In Proceedings of the 20th International EURO Mini Conference" Continuous Optimisation and Knowledge-Based Technologies" (pp. 444-449).

O’Donnell, T., Humphreys, P., McIvor, R., \& Maguire, L. (2009). Reducing the negative effects of sales promotions in supply chains using genetic algorithms.Expert Systems with Applications, 36(4), 7827-7837.

Potter, A., \& Disney, S. M. (2006). Bullwhip and batching: An exploration.International Journal of Production Economics, 104(2), 408-418.

Riddalls, C. E., \& Bennett, S. (2002). The stability of supply chains.International Journal of Production Research, 40(2), 459-475.

Sucky, E. (2009). The bullwhip effect in supply chains-An overestimated problem?. International Journal of Production Economics, 118(1), 311-322.

Wu, D. Y., \& Katok, E. (2006). Learning, communication, and the bullwhip effect. Journal of Operations Management, 24(6), 839-850.

Zhou, G., Min, H., \& Gen, M. (2002). The balanced allocation of customers to multiple distribution centers in the supply chain network: a genetic algorithm approach. Computers \& Industrial Engineering, 43(1), 251-261. 